\title{
Targeted intervention of elF4A 1 inhibits EMT and metastasis of pancreatic cancer cells via c-MYC/miR-9 signaling
}

\author{
Yuchong Zhao ${ }^{1 \dagger}$, Yun Wang ${ }^{1,2+}$, Wei Chen ${ }^{1}$, Shuya Bai', Wang Peng ${ }^{1}$, Mengli Zheng ${ }^{1}$, Yilei Yang ${ }^{1}$, \\ Bin Cheng ${ }^{1^{*}}$ (D) and Zhou Luan ${ }^{1^{*}}$
}

\begin{abstract}
Background: Owing to the lack of effective treatment options, early metastasis remains the major cause of pancreatic ductal adenocarcinoma (PDAC) recurrence and mortality. However, the molecular mechanism of early metastasis is largely unknown. We characterized the function of eukaryotic translation initiation factors (elFs) in epithelial-mesenchymal-transition (EMT) and metastasis in pancreatic cancer cells to investigate whether elFs and downstream c-MYC affect EMT and metastasis by joint interference.

Methods: We used The Cancer Genome Atlas (TCGA) and Genome Tissue Expression (GTEx) databases to analyze elF4A1 expression in PDAC tissues and further validated the findings with a microarray containing 53 PDAC samples. Expression regulation and pharmacological inhibition of elF4A1 and c-MYC were performed to determine their role in migration, invasion, and metastasis in pancreatic cancer cells in vitro and in vivo.

Results: Elevated elF4A1 expression was positively correlated with lymph node infiltration, tumor size, and indicated a poor prognosis. elF4A1 decreased E-cadherin expression through the c-MYC/miR-9 axis. Loss of elF4A1 and c-MYC decreased the EMT and metastasis capabilities of pancreatic cancer cells, whereas upregulation of elF4A1 attenuated the inhibition of EMT and metastasis induced by c-MYC downregulation. Treatment with the elF4A1 inhibitor rocaglamide (RocA) or the c-MYC inhibitor Mycro3 either alone or in combination significantly decreased the expression level of EMT markers in pancreatic cancer cells in vitro. However, the efficiency and safety of RocA alone were not inferior to those of the combination treatment in vivo.
\end{abstract}

Conclusion: Overexpression of elF4A1 downregulated E-cadherin expression through the c-MYC/miR- 9 axis, which promoted EMT and metastasis of pancreatic cancer cells. Despite the potential feedback loop between elF4A1 and C-MYC, RocA monotherapy is a promising treatment inhibiting elF4A1-induced PDAC metastasis.

Keywords: Eukaryotic translation initiation factor 4A1, c-MYC, Epithelial-mesenchymal transition, Rocaglamide, Mycro3

\footnotetext{
*Correspondence: b.cheng@tjh.tjmu.edu.cn; luanzhoutj@163.com †Yuchong Zhao and Yun Wang contribute equally to this article ${ }^{1}$ Department of Gastroenterology and Hepatology, Tongji Hospital, Tongji Medical College, Huazhong University of Science and Technology, Jiefang Avenue No. 1095, Wuhan 430030, China

Full list of author information is available at the end of the article
}

\section{Introduction}

Pancreatic ductal adenocarcinoma (PDAC) is universally one of the most lethal solid malignancies. Despite its relatively low incidence, PDAC remains the fourth leading cause of cancer-related death in developed countries $[1,2]$, with no significant changes in the mortality to incidence ratio in the past several decades and original author(s) and the source, provide a link to the Creative Commons licence, and indicate if changes were made. The images or other third party material in this article are included in the article's Creative Commons licence, unless indicated otherwise in a credit line to the material. If material is not included in the article's Creative Commons licence and your intended use is not permitted by statutory regulation or exceeds the permitted use, you will need to obtain permission directly from the copyright holder. To view a copy of this licence, visit http://creativecommons.org/licenses/by/4.0/. The Creative Commons Public Domain Dedication waiver (http://creativecommons.org/publicdomain/zero/1.0/) applies to the data made available in this article, unless otherwise stated in a credit line to the data. 
a five-year survival rate stagnating at approximately $3-15 \%$ [3]. At the early stage of carcinogenesis, pancreatic cancer cells can metastasize to distant organs through epithelial-mesenchymal transition (EMT) [4]. An overwhelming majority of patients diagnosed with PDAC have already lost the chance to undergo surgical resection due to early metastasis, which is also the key reason for postoperative recurrence. KRAS was the most commonly mutated oncogenes associated with PDAC [5]. To date, all attempts to target common PDAC KRAS variants (e.g., G12D, G12V, G12R) and KRAS downstream kinases (e.g., RAF, MEK, ERK, PI3K) have failed in phase I/II clinical trials [6-9]. Thus, novel therapeutics other than inhibitors targeting KRAS-associated kinases are urgently needed for PDAC patients.

Uncontrolled protein production is a common characteristic of cancer cells, and it is also necessary for EMT and metastasis [10]. Therefore, intervening to slow the hyperactive protein production has become a possible therapeutic strategy for PDAC. Translation initiation regulated by eukaryotic translation initiation factors (eIFs) is the most important rate-limiting step in translation $[11,12]$. Dysregulation of eIF expression and function is a hallmark of various types of cancers including PDAC; the eIF4F heterotrimeric complex is the main factor facilitating mRNA translation. Meanwhile, eIF4F activity is largely regulated by RAS signaling, which further indicates that eIF could play an important role in PDAC [13, 14]. The eIF4F complex is composed of the scaffold protein eIF4G, cap-binding protein eIF4E, and ATP-dependent DEAD-box RNA helicase eIF4A. Previous studies typically targeted eIF4E to inhibit EMT and metastasis of cancer cells, because eIF4E is generally overexpressed in multiple cancers. However, recent studies demonstrated that there are eIF4E-independent and eIF4A-dependent binding sites for oncogenic mRNA downstream of eIFs, including c-MYC, which could explain why studies targeting eIF4E were unsuccessful $[15,16]$. eIF4A is the only regulatory enzyme-catalytic factor in the eIF family, and facilitates unbinding the complex long-sequence helix (CLSH) in mRNA $5^{\prime}$-untranslated region (5'-UTR). The $\mathrm{CLSH}$ is a typical signature of various mRNAs downstream of eIFs, including c-MYC [17]. Overexpression of c-MYC is a carcinogenesis driver for multiple cancers and c-MYC is the most activated oncogenes [18, 19]. c-MYC is a crucial regulator of EMT and metastasis by promoting miR-9 expression [20, 21]. However, due to the structure of c-MYC, there are few c-MYC targeted inhibitors to dare $[22,23]$. Considering that eIF4A is dispensable for c-MYC translation, we hypothesized that interfering with eIF4A function could be an effective way to inhibit c-MYC.
Traditional Chinese medicinal herbs have garnered increasing attention as a novel source of anticancer remedies within the past decade. Rocaglamide (RocA) is a cyclopenta-b-benzofuran-type compound derived from traditional Chinese remedies genus Aglaia (family Meliaceae). Iwasake et al. conducted a survey in 2016 and found that RocA could firmly bind eIF4A at the $5^{\prime}$-UTR sequence and suppress hyperactive protein production more effectively than eIF4E intervention [24]. Subsequently, RocA was used to treat various hematologic malignancies (e.g., myeloma and T-cell lymphoma) in a mouse model and exerted prominent antitumor efficacy without observed side effects [25]. Trials of RocA in solid malignancies are rare, one of which was our previous study demonstrating that RocA obviously repressed EMT and metastasis of pancreatic cancer cells in a mouse model [26]. Nevertheless, how eIF4A affects EMT and metastasis of PDAC is still largely unknown. Considering the complex feedback loop between eIF4A and c-MYC, whether simultaneous inhibition of eIF4A and c-MYC was superior to targeting either alone merits investigation. There are 3 identified isoforms eIF4A in humans. eIF4A1 is the major type that participates in the assembly of eIF4F in cancer cells. eIF4A2, which is mainly expressed in cells with low levels of proliferation, is correlated with a good prognosis in multiple cancers [12, 17]. And the regulatory role of eIF4A3 remains largely elusive in cancer cells [27]. Therefore, we selected eIF4A1 as the target in our experiments.

Here, we reported that eIF4A1overexpression downregulated the expression of E-cadherin through c-MYC/ miR-9 signaling axis, which promoted EMT and metastasis.

\section{Materials and methods \\ Cell culture and reagents}

An immortalized pancreatic ductal epithelial cell line (HPDE) and pancreatic cancer cell line (Canpan-2) were obtained from the Cell Bank of the Chinese Academy of Sciences (Shanghai, China), and the pancreatic cancer cell lines AsPC-1, BxPC-3, and Panc-1 were purchased from the American Type Culture Collection (VA, USA). Cells were cultured in RPMI-1640 medium (GIBCO, NY, USA) supplemented with $10 \%$ fetal bovine serum (FBS, GIBCO) and $1 \%$ penicillin/streptomycin (Invitrogen) at $37{ }^{\circ} \mathrm{C}$ in a $5 \% \mathrm{CO}_{2}$ incubator. The eIF4A inhibitor RocA and c-MYC inhibitor Mycro3 were purchased from MedChemExpress (MCE, USA).

\section{Patient' follow-up and specimens collection}

This study was approved by the Ethics Committee of Tongji Hospital of Tongji Medical College, Huazhong University of Science and Technology (TJ-IRB20210927). 
All patients were completely informed of the possible use of their clinical information/specimens and we obtained full consent for the study. The cohort comprised 53 patients with PDAC who underwent surgical resection from 2009 to 2013 at the Department of Pancreatic and Hepatobiliary Surgery, Tongji Hospital of Tongji Medical College, Huazhong University of Science and Technology (Wuhan, China). All PDAC specimens were verified by pathologists and met the criteria set by the American Pancreatic Association. None of the patients underwent preoperative neoadjuvant therapy. The patients were evaluated every 3 months during the first 3 years and every 6 months thereafter by physicians who were blinded to the study parameters. Follow-up data were summarized at the end of December 2020. To evaluate the prognostic role of eIF4A1, tissue microarrays of the 53 PDAC samples were collected for further analysis.

\section{Immunohistochemistry (IHC)}

IHC staining with the eIF4A1 antibody (Abcam ab31217) was performed to detect the protein expression level. ImageJ (http://imagej.nih.gov/ij) IHC profiler (http:// sourceforge.net/projects/ihcprofiler) was used to assess IHC staining of the microarray based on two categories: staining intensity and percentage of staining. The staining intensity was scored as follows: negative (0 points), weakpositive (1 point), positive ( 2 points), and strong-positive (4 points). The protein expression level was quantified by multiplying the staining intensity and corresponding extents of positive staining ( $\mathrm{n} \%$ : percentage of positive areas to the whole areas). Then we divided the patients into two groups (score $<50$, low expression; score $>50$, high expression) and performed subsequent survival analysis. The IHC staining results were reassessed by two independent pathologists who were blinded to this study.

\section{Immunofluorescence}

Paraformaldehyde fixed samples were washed 3 times with ice-cold PBS for 3 min each time and then incubated in 10\% donkey serum in PBS for 20 min. Subsequently, the samples were incubated with the eIF4A1 antibody (Abcam ab31217) in PBS at $4{ }^{\circ} \mathrm{C}$ overnight. After washing, fluorochrome-conjugated secondary antibodies (1:400, Alexa Fluor ${ }^{\circledR} 488$ donkey anti-rabbit IgG) were used, and then the samples were treated with DAPI. The fluorescence was visualized under an Olympus microscope.

\section{Lentiviral transduction}

The lentivirus pLVX-Puro (Addgene) was obtained from DesignGene Biotechnology (Shanghai, China) and used to clone shRNA sequences. The vectors were designated Lv-eIF4A1 (eIF4A1-1， 5'-CACACTGGACTAGTGGAT
CCCGCCACCATGTCTGCGAGCCAGGATTCCC-3'; eIF4A1-2, 5'-AGTCACTTAAGCTTGGTACGATGA GGTCAGCAACATTGAGG-3'), Lv-sh-c-MYC (c-MYC1, 5'-GCTTCACCAACAGGAACTATG-3'; c-MYC-2, 5'-GCTTGTACCTGCAGGATCTGA-3'; c-MYC-3, 5'-GGAAACGACGAGAACAGTTGA-3') and Lv-shcontrol (empty vector). The lentivirus plasmid and packaging plasmids were transfected into pancreatic cancer cells with transfection reagent (Lipofectamine ${ }^{\circledR} 3000$, Thermo Fisher Scientific) in OPTI-MEM media (Invitrogen, MA, USA). Lentiviral infection of the target cells was performed in cell culture medium containing $5 \mu \mathrm{g} / \mathrm{ml}$ polybrene (Sigma H9268), and infected cells were selected with $2.5 \mu \mathrm{g} / \mathrm{ml}$ puromycin for follow-up experiments.

\section{Quantitative real-time PCR (RT-qPCR)}

cDNA was created with PrimeScript ${ }^{\mathrm{TM}} \mathrm{RT}$ reagent Kit Perfect Real Time, (Takara, RR037A) according to the manufacturer's protocol. Quantitative PCR was performed on a StepOne Real-Time System (Thermo Fisher Scientific) using TB Green ${ }^{\circledR}$ Premix EX Taq ${ }^{\mathrm{TM}}$ (Takara, RR820a) according to the manufacturer's protocol. Melting curve analysis was performed and the amplification plots were evaluated by SDS 1.9.1 software (Applied Biosystems, MA, USA). The $2^{-\Delta \Delta \mathrm{Ct}}$ method was used to determine relative fold changes in target gene expression from replicate samples. The bulge-loop primer for miR-9 was provided by RioBIO (Guangzhou, China).

\section{Western blot}

Western blot analysis was performed as described previously [28]. The primary antibodies targeted eIF4A1 (Abcam ab31217), c-MYC (Abcam ab32072), snail (Abcam ab216347), E-cadherin (Abcam ab40772), and $\beta$ actin (Abcam, ab8226). Protein bands were visualized using Beyo ECL Plus and quantified with ImageJ.

\section{Transient transfection}

Cells were transinfected with scramble siRNA or siRNA targeting eIF4A1 (siRNA1, 5'-GAGTAACTGGAA TGAGATT-3'; siRNA-2, 5'-TCCAGCAGCGAGCCA TTC-3'; $\quad$ siRNA-3, 5'-CGTGTGTTTGATATGCTT A-3') and c-MYC (siRNA-1, 5'-GAGGAGACATGG TGAACCA-3'; siRNA-2, 5'-GGGTCAAGTTGGACA GTGT-3'; siRNA-3, 5'-CGACGAGACCTTCATCAA A-3') with Lipofectamine ${ }^{\circledR} 3000$ (Thermo Fisher Scientific) and OPTI-MEM (Invitrogen, MA, USA) according to the manufacturer's protocol. eIF4A1-siRNA-1 and c-MYC-siRNA-3 were the most effective in knocking down their respective targets and were used for further analysis. Cells were transfected with CV567 empty vector, pcDNA3.1-eIF4A1 (P1，5'-CACACTGGACTA 
GTGGATCCCGCCACCATGTCTGCGAGCCAGGAT TCCC-3') or pcDNA3.2-c-MYC plasmids (P1, 5'-CAC ACTGGACTAGTGGATCCCGCCACCATGGATTTT TTTCGGGTAGTGG-3') using the transfection reagent Lipofectamine ${ }^{\circledR} 3000$ (Thermo Fisher Scientific) and OPTI-MEM (Invitrogen, MA, USA) according to the manufacturer's protocol.

\section{In vitro migration and invasion assay}

Cell migration and invasion were analyzed using Transwell chambers $(8-\mu \mathrm{m}$ pore size; Millipore, Billerica, MA, USA) with and without a Matrigel (BD Biosciences, San Jose, CA, USA) matrix in the upper chamber. Four groups of AsPC-1 cells were pretreated in DMSO, RocA $(100 \mathrm{nM})$, Mycro3 (5000 nM), and combination treatment solutions for $4 \mathrm{~h}$. Then the cells were seeded FBSfree culture medium in the upper chamber with $10 \%$ FBS culture medium in the lower chamber as a chemoattractant. After $28 \mathrm{~h}$ (Migration) or $32 \mathrm{~h}$ (Invasion) of incubation, cells on the lower surface of the membrane were washed with PBS, fixed in $4 \%$ methanol, and stained with a $0.4 \%$ crystal violet solution. Photographs of three randomly selected fields of the fixed cells were captured and cells were counted. The experiments were repeated independently three times.

\section{CCK8 assay}

The sensitivity of cells to RocA and Mycro3 either or in combination was measured by CCK8 assay. Cells were seeded in a 96-well plate at density of 1000 cells per well and then treated with the treatment concentrations (RocA, $100 \mathrm{nM}$; Mycro3, $5000 \mathrm{nM}$ ). After the cells were attached. Then incubated for $4 \mathrm{~h}$, replace fresh $1640 \mathrm{cul}-$ ture medium and cell counting kit-8 (CCK8, promoter, China) to each well according to the manufacturer's protocol, incubated at $37{ }^{\circ} \mathrm{C}$ for $2 \mathrm{~h}$. Absorbance was measured at $450 \mathrm{~nm}$ using a microplate reader (Thermo Scientific).

\section{Establishment of a metastatic mouse model}

Animal experiments were approved by the Ethics Committee of Tongji Hospital of Tongji Medical College, Huazhong University of Science and Technology (TJH202010007). Four-week-old female severe combined immune deficiency (SCID) mice (Charles River Co., Beijing) were maintained in a specific pathogen-free (SPF) environment. To establish the metastatic mouse model in vivo, $2 \times 10^{6}$ AsPC- 1 cells in $200 \mu \mathrm{l}$ were intravenously injected via caudal vein into each animal. Small animal imaging (Spectral Imaging LagoX) was performed every 3 days after cell injection and the mice were randomly divided into different groups (5/ group). RocA (MCE, USA) was administered daily by intraperitoneal injection $(5 \mathrm{mg} / \mathrm{kg} / \mathrm{d}, 3 \mathrm{mg}$ RocA dissolved in $30 \mu \mathrm{l}$ DMSO, $600 \mu \mathrm{l}$ PEG300 and $75 \mu \mathrm{l}$ Tween- 80 successively, and then adjusted to a volume of $1.5 \mathrm{ml}$ with normal saline) every day originally [26], then adjusted to $2.5 \mathrm{mg} / \mathrm{kg} / \mathrm{d}$ once on an alternate day. Mycro3 was administered intragastrically $(100 \mathrm{mg} /$ $\mathrm{kg} / \mathrm{d}, 25 \mathrm{mg}$ mycro3 dissolved in $2.5 \mathrm{ml}$ of $0.5 \%$ methylcellulose solution and subject to ultrasonication) [29]. Control mice were treated with intragastric $200 \mu \mathrm{l}$ of methylcellulose solution daily and $100 \mu \mathrm{l}$ of methylcellulose solution via intraperitoneal injection once on an alternate day. When the total body weight loss was $>20 \%$, the mice were sacrificed by cervical vertebra dislocation under deep sedation conditions using $70 \mathrm{mg} / \mathrm{kg}$ pentobarbital sodium (peritoneal injection).

\section{Subcutaneous xenografts in nude mice}

Four-week-old nude mice were obtained from HFK Bioscience Ltd (Beijing, China) and maintained in SPF conditions. AsPC-1 cells $\left(5.0 \times 10^{6}\right)$ suspended in a $100 \mu \mathrm{l}$ solution comprising equal volumes of medium and matrix gel were subcutaneously implanted into the right flanks of 6-week-old female nude mice. When the tumors had reached a volume of approximately 60-90 $\mathrm{mm}^{3}$, the mice were then randomly divided into two groups. The treatment group received an intraperitoneal injection of RocA (previously adjusted dose), whereas the control group received cosolvent injection alone $(\mathrm{n}=4$, the treatments were carried out once daily for 28 days. The tumor volumes and total body weight of the animals were measured twice a week. The tumor volumes $\left(\mathrm{mm}^{3}\right)$ were calculated with the following formula: $\mathrm{V}=\mathrm{LS}^{2} / 2$ (where $\mathrm{L}$ is the longest diameter and $\mathrm{S}$ is the shortest diameter). At the end of the experiment, the mice were sacrificed and the tumors were harvested for western blot analysis. The mice were sacrificed 4 weeks after implantation by cervical dislocation under deep sedation conditions using $70 \mathrm{mg} / \mathrm{kg}$ pentobarbital sodium (peritoneal injection).

\section{Statistical analysis}

The data are representative of at least three independent experiments or multiple independent mice as indicated. The patient characteristics were summarized as the mean \pm standard deviation (SD) for normally distributed continuous variables, median with interquartile range for continuous variables with a skewed distribution, and frequency (percentage) for categorical variables. All analyses were performed using R (http://www.R-project. org, version 3.5.2) with a two-sided significance threshold of $P<0.05$. 


\section{Results}

elF4A1 was highly expressed in PDAC and predicted a poor prognosis

First, we analyzed eIF4A1 expression across multiple cancers using data from Gene Expression Profiling Interactive Analysis (GEPIA, http://gepia.cancer-pku.cn/). eIF4A1 was highly expressed in multiple cancer types, including pancreatic adenocarcinoma, thymoma, glioblastoma multiforme, diffuse large B cell lymphoma, and testicular germ cell tumors (Fig. 1a). To evaluate the expression of all eIF family members in pancreatic adenocarcinoma, we analyzed the RNA-seq data from the TCGA and GTEx databases. Two samples were deleted after data quality control, resulting in 179 pancreatic tumor tissues and 169 normal pancreatic tissues. We ranked the differential expression of all eIFs (Fig. 1b) and the results showed that the expression level of eIF4A1 in pancreatic tumor tissues was significantly higher than that in normal tissues (Fig. 1c).

Subsequently, we analyzed the prognostic role of eIF4A1 in PDAC patients. Immunofluorescence results indicated that eIF4A1 was mainly localized in the cytosol (Fig. 1d), which was consistent with its function in assisting translation initiation. The fluorescence intensity in the more aggressive AsPC-1 cell line was significantly higher than that in Capan-2 cells. We used IHC to detect eIF4A1 expression in a tissue microarray comprising samples from 53 patients with pathologically confirmed PDAC from 2009 (Fig. 1e). The results indicated that patients with high eIF4A1 expression had a poor prognosis, and the median overall survival of patients with high eIF4A1 expression was significantly shorter than that of patients with low eIF4A1 expression (6.0 months vs. 9.0 months, $\mathrm{HR}=2.10,95 \% \mathrm{CI}: 1.44-5.24, \mathrm{P}=0.0061)$ (Fig. 1f). Furthermore, we examined the correlations between eIF4A1 expression and multiple clinical features (Table $1, " P<0.05$; chi-square or Fisher's exact test). Importantly, we found that a high level of eIF4A1 expression was significantly correlated with tumor size and lymph node metastasis. In summary, these results showed that eIF4A1 was highly expressed in pancreatic adenocarcinoma tissues, and high expression of eIF4A1 suggested a poor prognosis. The eIF4A1 expression was positively correlated with lymph node metastasis which is a major mechanism of cancer cell metastasis.

\section{elF4A1 targeted c-MYC to regulate metastasis in pancreatic cancer cells}

To elucidate the mechanism by which eIF4A1 regulates the biological behavior of tumor cells, we searched

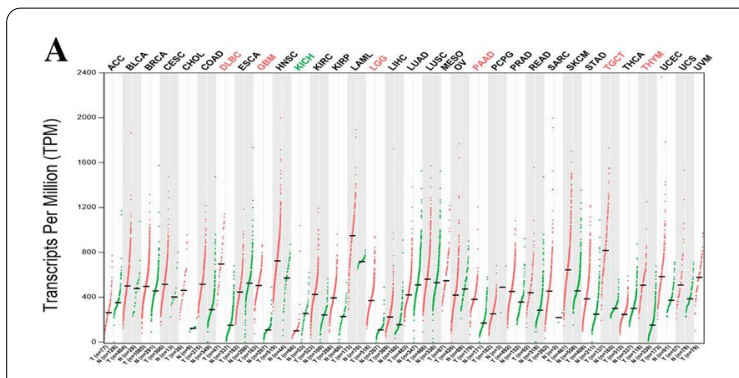

B
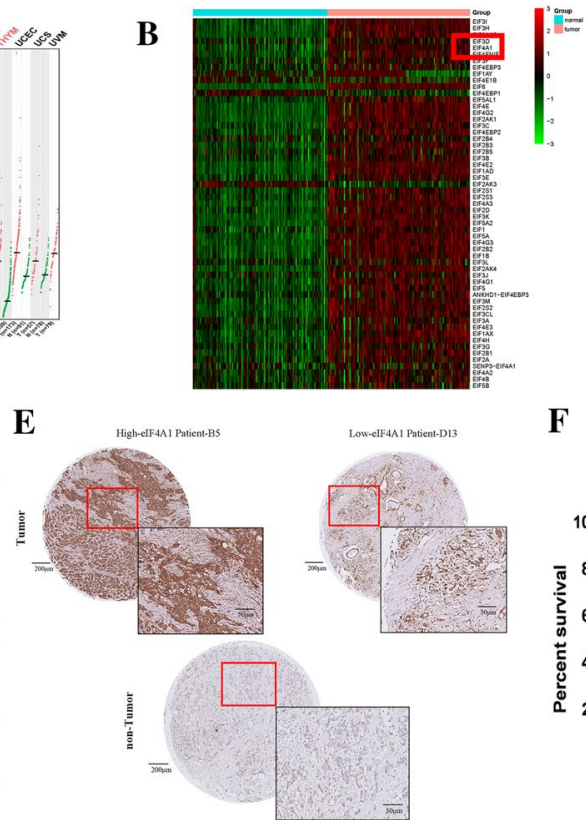

$\mathbf{F}$
E
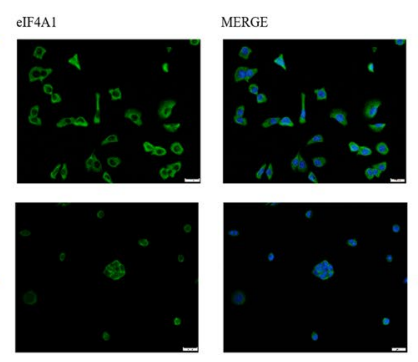

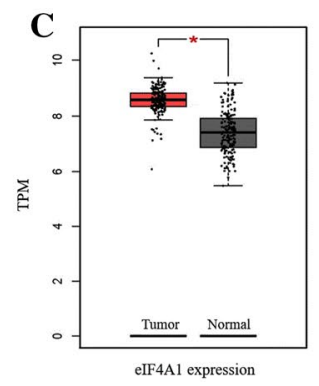

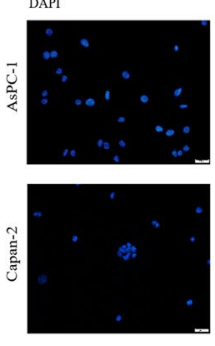

Fig. 1 Analysis of the correlation of elF4A1 expression and clinical characteristics of patients. a elF4A1 expression was upregulated in various cancer types including pancreatic adenocarcinoma; $\mathbf{b}$ elF4A1 was one of the top-upregulated genes of the protein synthesis-related elF family in PDAC compared to healthy pancreatic tissues; $\mathbf{c}$ elF4A1 was significantly overexpressed in PDAC tissues, $\log _{2}[F C]=1.162, P=2.22 \mathrm{e}-16$; $\mathbf{d}$ Immunofluorescence image of elF4A1 localization (green) in pancreatic cancer cells (AsPC-1, Capan-2). elF4A1 was predominantly located in the cytoplasm; e Representative images of IHC staining for elF4A1 in a microarray comprising tumor and adjacent nontumor tissues, Scale bars: $100 \mu \mathrm{m}$. f Analysis of overall survival was compared according to the expression levels of elF4A1 in PDAC tissues. Patients with high elF4A1 expression had shorter overall survival (6 months vs. 9 months, log-rank test, $\mathrm{HR}=2.096,95 \% \mathrm{Cl}: 1.438-5.242, P=0.0061$ ) 
Table 1 Correlation between elF4A1 expression and clinical characteristics of PDAC patients

\begin{tabular}{|c|c|c|c|}
\hline Clinical characteristics & High-elF4A1 & Low-elF4A1 & $P$-value \\
\hline Age, mean $\pm S D$, years & $66.04 \pm 9.69$ & $64.10 \pm 10.07$ & 0.482 \\
\hline Male, n (\%) & $13(56.53 \%)$ & $21(70.00 \%)$ & 0.311 \\
\hline $\begin{array}{l}\text { Overall survival, median, } \\
\text { months }\end{array}$ & $6.0(4.0,9.0)$ & $9.0(8.0,15.5)$ & $0.006^{b}$ \\
\hline Differentiation status & & & 0.523 \\
\hline Well differentiated & $11(20.75 \%)$ & $17(32.08 \%)$ & \\
\hline $\begin{array}{l}\text { Moderately to poorly dif- } \\
\text { ferentiated }\end{array}$ & $12(22.64 \%)$ & $13(24.53 \%)$ & \\
\hline Tumor size, mean $\pm \mathrm{SD}, \mathrm{cm}$ & $4.57 \pm 1.40$ & $3.75 \pm 1.28$ & $0.032^{b}$ \\
\hline Recurrences, n (\%) & $17(73.91 \%)$ & $20(66.67 \%)$ & 0.569 \\
\hline Location & & & 0.267 \\
\hline Head, n (\%) & $15(28.30 \%)$ & $18(33.96 \%)$ & \\
\hline Body/tail, n (\%) & $7(13.21 \%)$ & $20(37.74 \%)$ & \\
\hline Diffusion involvement, n (\%) & $1(1.89 \%)$ & $2(3.77 \%)$ & \\
\hline TNM stage $^{\mathrm{a}}$ & & & 0.077 \\
\hline I-II stage, n (\%) & 14 & 24 & \\
\hline III-IV stage, n (\%) & 9 & 5 & \\
\hline Lymph node metastasis, n (\%) & $14(63.64 \%)$ & $10(35.71 \%)$ & $0.0498^{*}$ \\
\hline Vascular Infiltration, n (\%) & $10(43.48 \%)$ & $3(10.00 \%)$ & 0.272 \\
\hline
\end{tabular}

${ }^{a}$ NCCN Version 3.2019 pancreatic adenocarcinoma

${ }^{b} P<0.05$, significant difference

the GEO database for all ribosome profiling data that included pancreatic cancer cells, and ultimately, dataset GSE120159 was selected for further analysis. The data included 3 Panc-1 cell samples treated with the rocaglate CR-31-B, a small-molecule inhibitor of the eIF4A helicase, and 3 Panc- 1 cell samples treated with DMSO. A differential expression analysis using $\mathrm{R}$ package DEseq2 identified 179 differentially expressed proteins (DEPs) between the CR-31-B-treated group and the DMSOtreated group, with a $p$-adjusted (FDR) value $<0.05$ and $\mid \log _{2} \mathrm{FC}$ (fold change) $\mid>1$ as the cutoff value. Among these proteins, 128 were downregulated and 51 were upregulated. The heatmap illustrates the proteins with the greatest changes in expression (overexpression and suppression) (Fig. 2a). The expression of c-MYC was significantly downregulated $\left(\log _{2} \mathrm{FC}=-1.05\right.$, $\mathrm{FDR}=0.00192)$ in the CR-31-B-treated group compared with the control group, ranking in the top $0.6 \%$ of all the lists of affected genes.

To further screen for the key target of eIF4A that promotes metastasis, we knocked down eIF4A1 expression (eIF4A1 siRNA) and analyzed the alternations of protein profile expression compared to that of the control group. Notably, the protein abundance at $49 \mathrm{kDa}$, which is the molecular weight of c-MYC remarkably decreased after of eIF4A1 knockdown (Additional file 1: Fig. S1). Importantly, we observed that c-MYC expression was positively correlated with eIF4A1 expression in PDAC and across various cancer types (Fig. 2b; $\mathrm{n}=44, r=0.5041$, $P=0.0005$, Spearman correlation; Additional file 2: Fig. S2).

Gene Ontology (GO) analysis using ribosomesequencing data revealed that the DEPs were significantly enriched in the GO terms for 497 biological processes (BPs), 56 cellular components (CCs), and 48 molecular functions (MFs) (Fig. 2c). We concluded that the DEPs were enriched in functions critical for metastasis, including signal transduction, cytoskeleton, lymph-angiogenesis, and cell junctions. Gene set enrichment analysis (GSEA) performed with ribosomal profiling showed that the enrichment of EMT-related gene sets was reduced significantly after CR-31-B treatment (Fig. 2d). These results indicated that eIF4A1 could target $\mathrm{c}-\mathrm{MYC}$ to regulate the biological behaviors of pancreatic cancer cells.

\section{elF4A1 promoted EMT and metastasis through c-MYC/ miR-9 signaling}

Recent studies have demonstrated that c-MYC promotes EMT by upregulating the expression of miR-9, which can competitively bind with E-cadherin encoding sequence of CDH1 and subsequently drive EMT [20,30]. Before exploring the role of eIF4A 1 and c-MYC in the regulatory effect in pancreatic cells, we analyzed eIF4A1 expression in the pancreatic cancer cell lines Panc-1, Capan-2, AsPC-1, and MiaPaca-2, and in the normal pancreatic ductal epithelial cell line HPDE. Western blot analysis showed that eIF4A1 was notably more highly expressed in the aggressive pancreatic cancer cell line AsPC-1 and relatively less expressed in the indolent Capan-2 cell line and normal HPDE cells (Fig. 3a). Therefore, we selected AsPC-1 and Capan-2 for the subsequent experiments. We knocked down eIF4A1 and c-MYC expression in AsPC-1 cells (eIF4A1 siRNA, c-MYC siRNA) and overexpressed eIF4A1 and c-MYC in Capan-2 cells (pcDNA3.1-eIF4A1, pcDNA3.2-myc). Western blot and qRT-PCR showed that eIF4A1 knockdown in AsPC-1 cells decreased the expression of EMT-related genes (c-MYC, snail, and miR-9) and increased the expression of E-cadherin (Fig. 3b). c-MYC knockdown resulted in the same changes in expression (Figure, 3c); however, repressing c-MYC expression did not influence eIF4A1 expression. Accordingly, eIF4A1 and c-MYC overexpression in Capan-2 cells showed expression patterns opposite of those observed in the knockdown experiments (Fig. 3d, e). Transwell migration and invasion assays revealed that AsPC-1 cells with eIF4A1 and c-MYCs knockdown displayed significantly lower migratory and invasive abilities (Fig. 3f), whereas these abilities were significantly increased in eIF4A1 and c-MYC overexpressing Capan-2 cells compared to those in control cells 

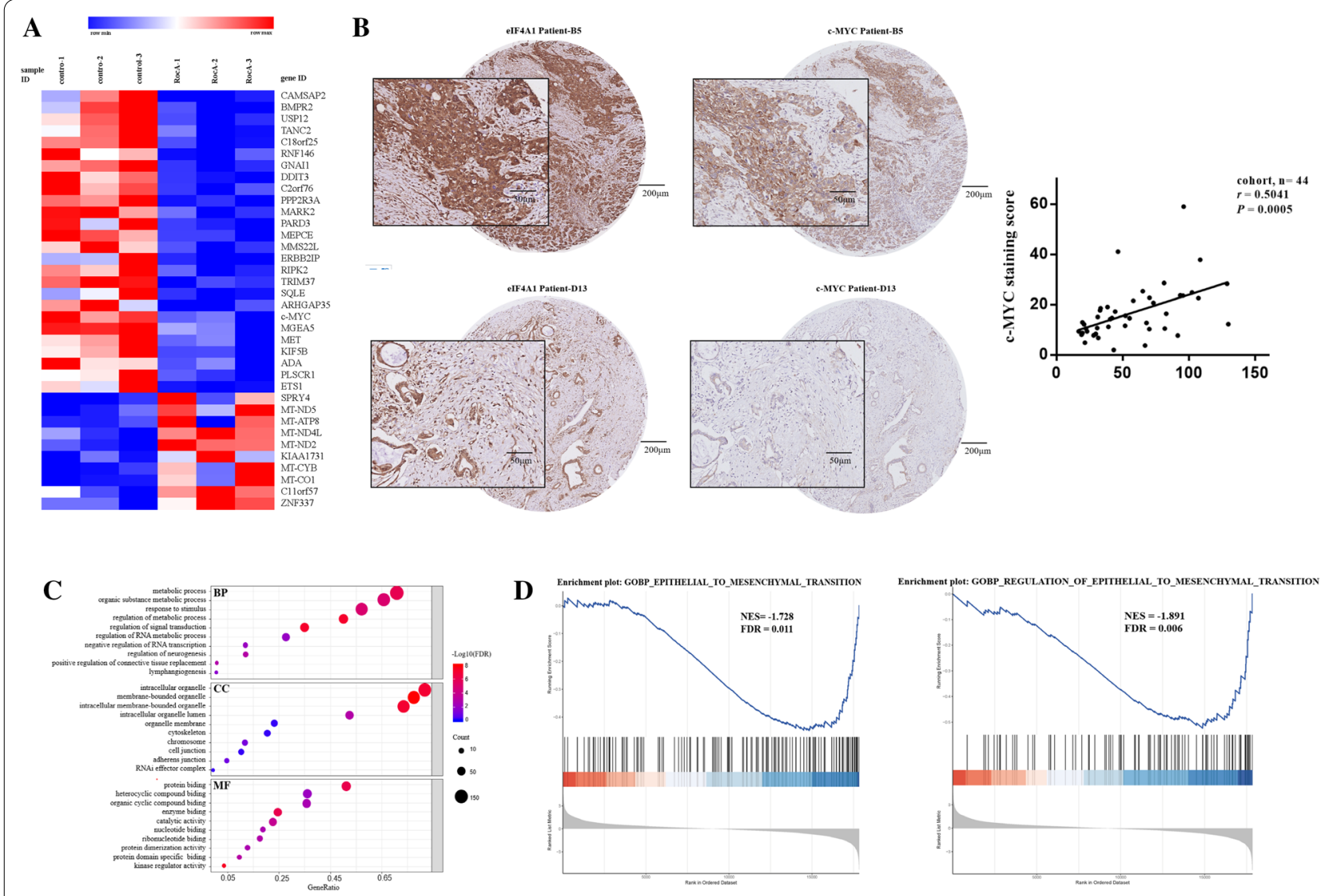

D
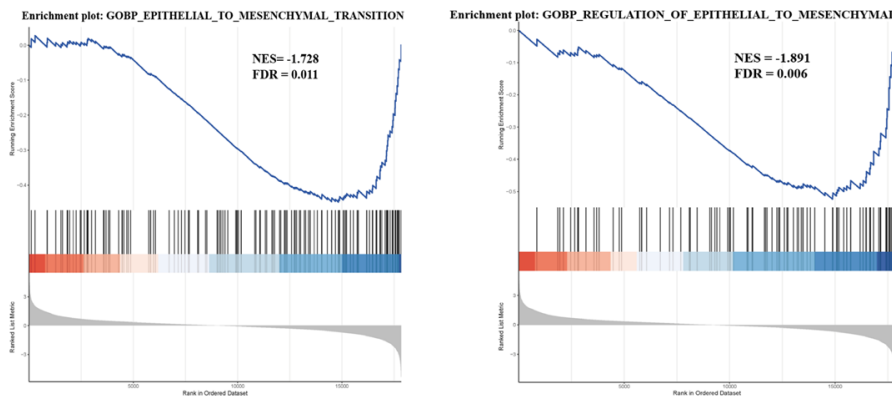

Fig. 2 Screening for the target of elF4A1 in PDAC. a c-MYC expression was significantly downregulated $\left(\log _{2} F C=-1.05, F D R=0.00192\right)$ in the rocaglate CR-31-B-treated group compared with the control group, ranking in the top $0.6 \%$ of all the regulated genes. $\mathbf{b}$ The expression of elF4A1 and C-MYC in tumor tissues from the same PDAC patients were analyzed by IHC staining and the results showed that c-MYC is positively correlated with elF4A1 ( $n=44, r=0.5041, P=0.0005$, Spearman correlation). $\mathbf{c}$ The DEPs were enriched in multiple metastasis-associated functions. $\mathbf{d}$ GSEA was performed with ribosomal sequencing results. Gene enrichment plots showed that the enrichment of EMT-related gene sets was reduced substantially after elF4A-intervention

(Fig. 3g). Based on the changes in the expression of EMTrelated molecules and the changes in the cells' migratory and invasive capabilities, these results indicated that eIF4A1 could promote EMT by targeting c-MYC/miR-9 signaling.

\section{Overexpression of elF4A1 increased the invasive, migratory, and metastatic capabilities of MYC-knockdown AsPC-1 cells in vitro and in vivo}

The relationship between eIF4A1 and c-MYC is not linear, recent studies revealed that overexpression of c-MYC could increase the level of eIF4A1 expression [15, 31]. To further explore the regulatory interactions between eIF4A1 and c-MYC, lentivirus was used to regulate eIFA1 and c-MYC expression in AsPC-1 cells. There were four groups: (1) e-U-M-D sequential regulation group (overexpression of eIF4A1 expression (Lv- eIF4A1) followed by c-MYC knockdown (Lv-sh-c-MYC)); (2) e-U group (overexpression eIF4A1 (Lv- eIF4A1)); (3) M-D group
(c-MYC knockdown (Lv-sh-c-MYC)); (4): vector group (Lv-sh-control).

Western blots showed that E-cadherin expression was significantly decreased in e-U AsPC-1 cells and significantly increased in the M-D AsPC-1 cells. The E-cadherin expression in e-U-M-D AsPC-1 cells was between that in the e-U and M-D cells but was still higher than the level in the vector group cells (Fig. 4a). Consistent with the trends of western blot results, Transwell migration and invasion assays showed that the migratory and invasive abilities of e-U-M-D cells were superior to those of the M-D cells but inferior to those of the vector and e-U cells (Fig. 4b). In vivo, the metastatic potentials of these cells were examined using a mouse metastasis model via caudal vein injection. The results revealed that the luminescence intensity of e-U-M-D cells was significantly higher than M-D group cells $(1.008 \mathrm{e}+10$ vs. $5.387 \mathrm{e}+9$, $P=0.0349)$, accordingly weaker to the e-U group cells $\left(1.008 \mathrm{e}_{+} 10\right.$ vs. $\left.2.410 \mathrm{e}_{+} 10, P=0.2369\right)$ (Fig. $4 \mathrm{c}$ ). 

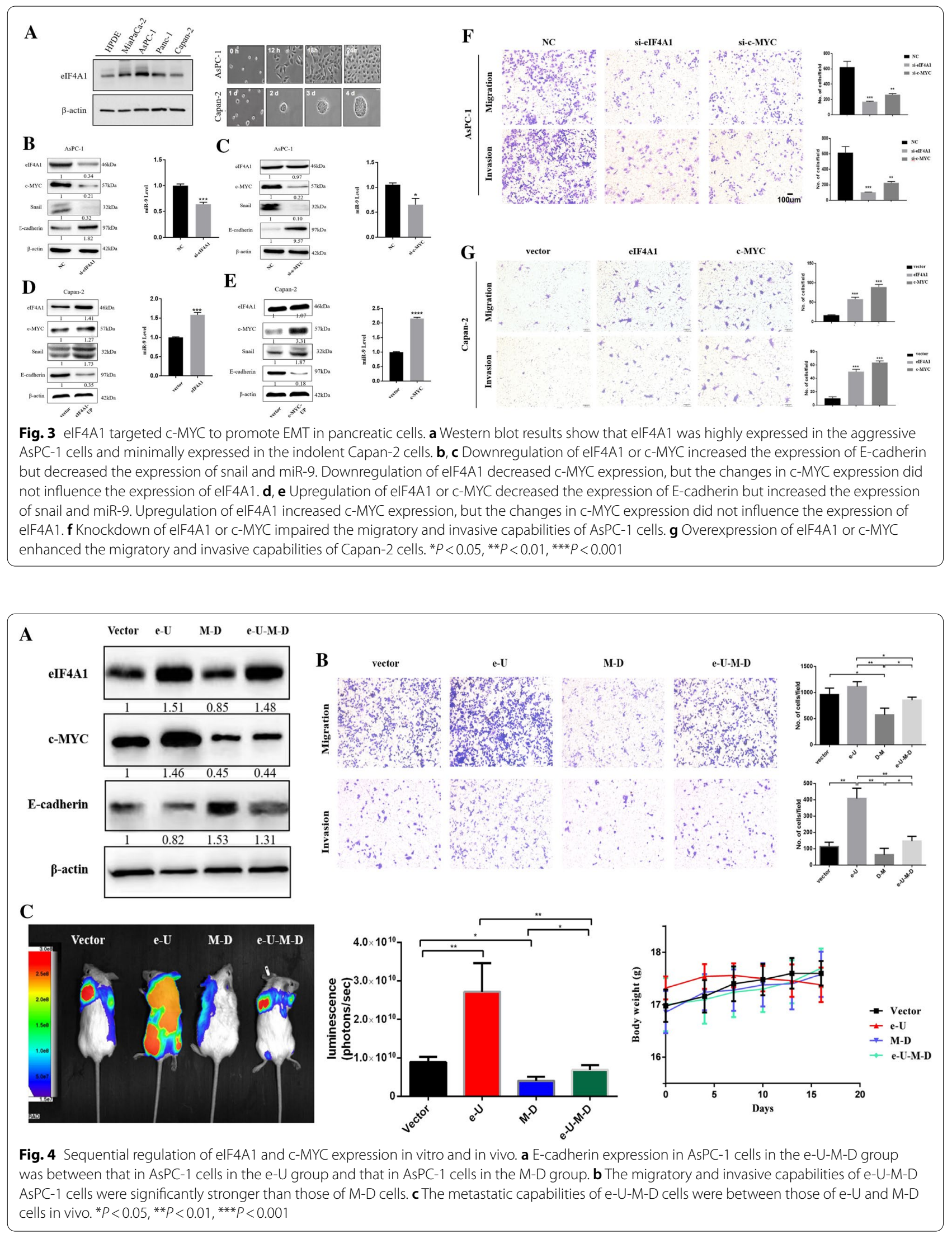
Collectively, the in vitro and in vivo results revealed that the level of EMT and metastatic capabilities of e-U-M-D cells were between those of the e-U cells and M-D cells. These results indicated that overexpression of eIF4A1 expression could attenuate the inhibition of MYC-downregulated pancreatic cancer cells of EMT and metastasis.

\section{RocA alone was not inferior to RocA plus Mycro3 joint intervention inhibiting EMT and metastasis in vitro and in vivo}

Our previous studies demonstrated that c-MYC was not the only target of eIF4A1 to promote EMT and metastasis. When c-MYC is repressed, eIF4A1 might exert a pro-EMT effect through other pathways to compensate for this inhibition. Considering the complex feedback relationship between eIF4A1 and c-MYC, we implemented a combination treatment comprising RocA (an eIF4A1 inhibitor) and Mycro3 (a c-MYC inhibitor) to explore whether the combination is superior to either monotherapy.

To select the optimal drug concentration, we conducted a series of concentration gradient experiments. The western blot results showed that eIF4A1 expression decreased significantly in response to $100 \mathrm{nM}$ RocA and that c-MYC expression decreased significantly in response to 5000 nM Mycro3 (Fig. 5a). Crystal precipitates formed when the concentrations increased beyond the value in subsequent experiments; thus, we selected $100 \mathrm{nM}$ RocA and $5000 \mathrm{nM}$ Mycro3 in subsequent experiments. We established 4 treatment groups [(1) RocA + Mycro3; (2) RocA; (3) Myro3; (4) DMSO control] and compared their safety and efficacy. Western blots and qRT-PCR showed that all 3 intervention methods significantly increased E-cadherin expression and decreased c-MYC expression in AsPC-1 cells (Fig. 5b). Compared with the DMSO treated cells, CCK8 assay showed that pretreatment with RocA and Mycro3 either alone or in combination did not affect the death ratio of AsPC-1 cells (Fig. 5c). However, all 3 intervention methods remarkably decreased the migratory and invasive abilities and methods decreased the EMT level of pancreatic cancer cells compared with the control group (Fig. 5d; Additional file 3: Fig. S3). However, there was no statistically significant difference among the 3 groups.

To examine the efficiency and safety of the treatments in vivo, we injected mice with AsPC-1 cells via caudal vein. We found that the mortality rates of the RocA group $(40.0 \%)$ and combination group (62.5\%) were relatively high. Evaluation of mice after sacrifice showed multiple cases presenting nonocclusive intestinal dilation. Considering the possible intolerance due to the high dose and frequency of RocA administered, we decreased the dosage from $5 \mathrm{mg} / \mathrm{kg} / \mathrm{d}$ qd to $2.5 \mathrm{mg} / \mathrm{kg} / \mathrm{d}$ once on alternate days (still administered via intraperitoneal injection), while the dosage of Mycro3 remains $100 \mathrm{mg} / \mathrm{kg} / \mathrm{d}$ qd (administered intragastrically). The mice tolerated the modified regimen better without more deaths. The luminescence intensity from the RocA group was significantly weaker than that of the control group $(1.393 \mathrm{e}+9$ vs. $2.707 \mathrm{e}+9, P=0.0474)$. However, there were no significant differences in luminescence intensity between the control and both the Myro3 and combination groups (Fig. 5e). Taken together, these data demonstrated that the modified of RocA monotherapy exerted an obvious antimetastatic effect, superior to Mycro3 or the combination treatment.

To further evaluate the efficacy of RocA, we used a subcutaneous xenograft nude mouse model. Two-way ANOVA indicated that the tumor volumes of the RocA group were significantly smaller than those of the control group $(P<0.0001)$ (Fig. 5f) which suggested that RocA notably suppressed tumor growth. Western blot analysis showed that RocA markedly decreased the expression of eIF4a1, c-MYC, and snail and increased the expression of E-cadherin (Fig. 5g) in vivo.

\section{Discussion}

Various oncogenes associated with PDAC, including KRAS and its downstream kinases cannot be targeted because of their specific molecular structures [23, 32]. However, targeting translation has been an alternative approach for cancer treatment. Protein production in PDAC was verified to be hyperactive both in vivo and in organoids [33]. eIF4A, which participates in the assembly of eIF4F, is the nexus for translational regulation [13, 34]. Unlike KRAS, eIF4A can be targeted, and the curative effects of targeting eIF4A have been validated in several hematological malignancies [25, 35], positioning this molecule as an alternative treatment for PDAC. Recent studies revealed that eIF4A1 inhibition could significantly repress the tumor growth by remodeling metabolism and DNA replication [36, 37]. Here, we present a novel strategy for inhibiting EMT and metastasis in pancreatic cancer cells via c-MYC/miR-9 signaling.

Our previous study demonstrated that targeting eIF4A could significantly decrease the lung metastasis of pancreatic cancer cells in vivo [26]. Here we further elucidated the mechanism by which eIF4A promotes EMT and metastasis and verified that eIF4A1 was correlated with a worse prognosis. Considering the complex longsequence $5^{\prime}$-UTR structure of c-MYC mRNA, we showed that the regulation of c-MYC expression was highly dependent on eIF4A. Depletion of eIF4A1 significantly decreased the expression levels of c-MYC and EMT markers in vitro. Overexpression of eIF4A1 induced a decrease in E-cadherin expression through the c-MYC/ 

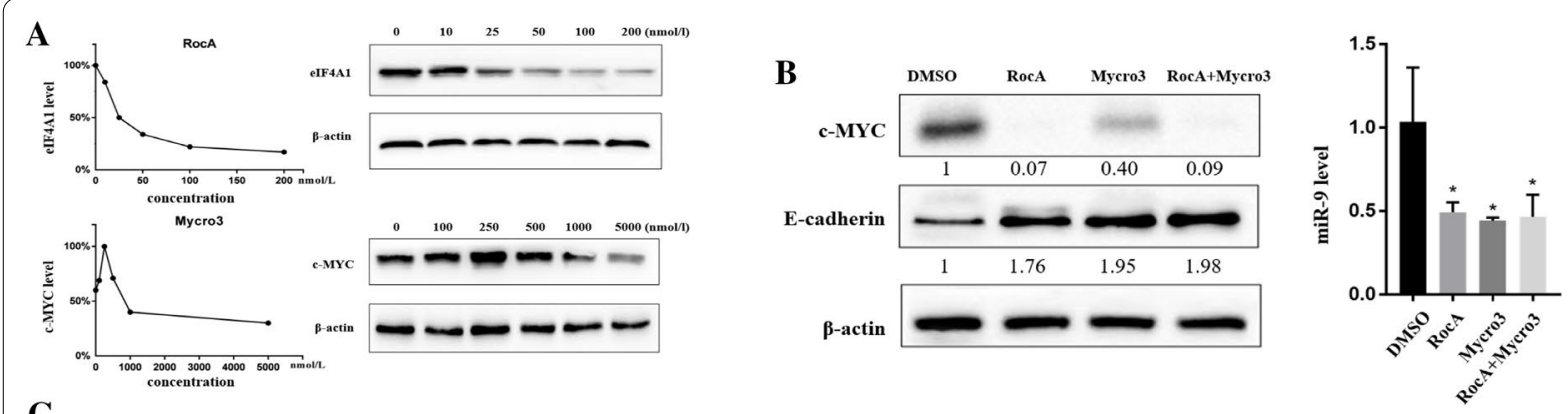

C
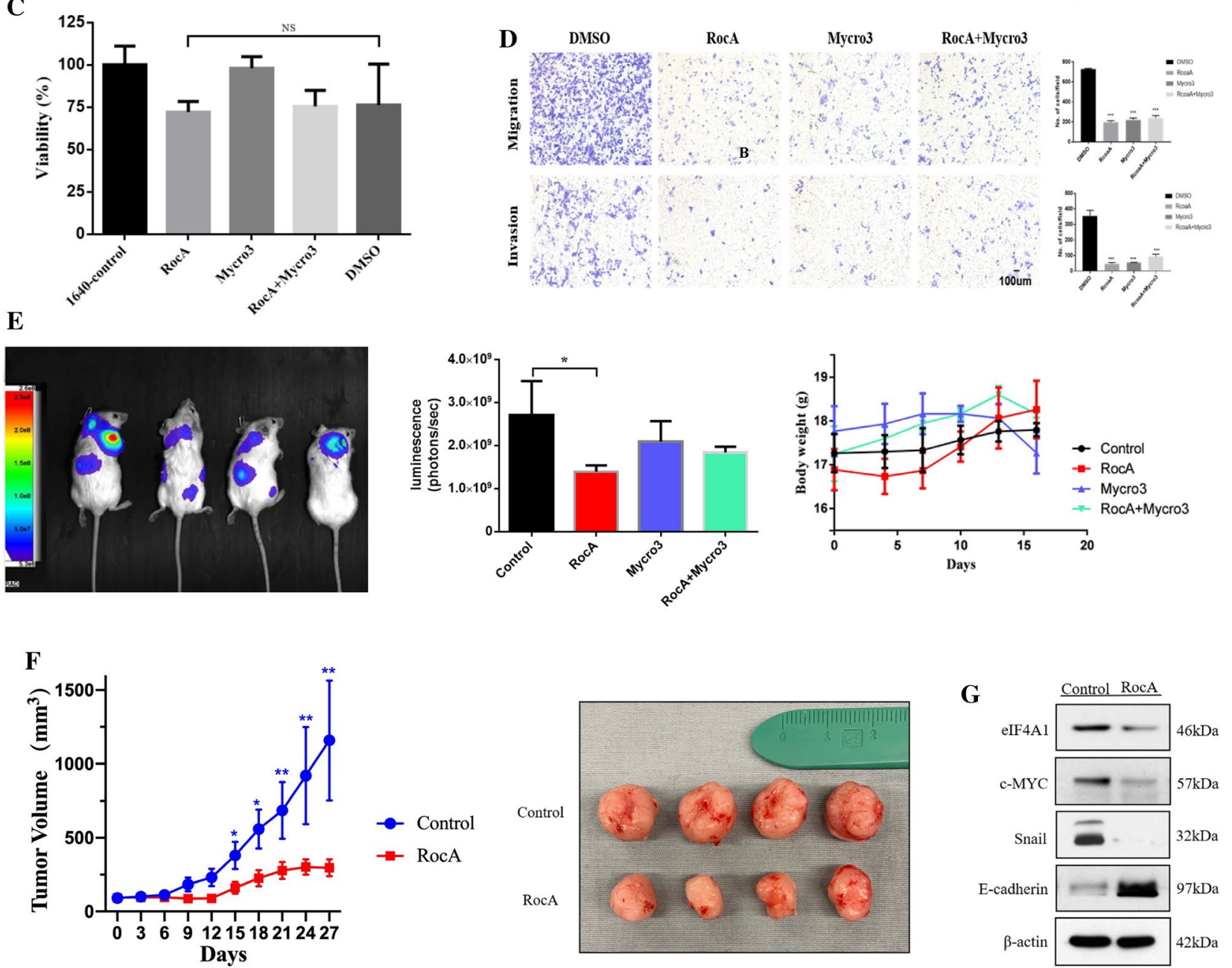

Fig. 5 RocA and Mycro3 suppressed EMT and metastasis in pancreatic cancer cells in vitro and in vivo. a The suitable concentrations for treatment were initially determined to be $100 \mathrm{nmol} / \mathrm{L}$ (RocA) and $5000 \mathrm{nmol} / \mathrm{L}$ (Mycro3). b Treatment with $100 \mathrm{nmol} / \mathrm{L}$ RocA and $5000 \mathrm{nmol} / \mathrm{L}$ Mycro3, and either alone or in combination significantly inhibited the expression of miR-9 and c-MYC in AsPC-1 cells. c AsPC-1 cells were treated with DMSO, RocA (100 nM), Mycro3 (5000 nM), and combination treatment for $4 \mathrm{~h}$ and evaluated by CCK8 assay. It showed that there were no significant differences of the death ratio among each treatment group. $\mathbf{d}$ Treatment with $100 \mathrm{nmol} / \mathrm{L}$ RocA and $5000 \mathrm{nmol} / \mathrm{L} \mathrm{Mycro3}$ either alone or in combination significantly decreased the migratory and invasive capabilities of AsPC-1 cells. There were no significant differences among the treatment groups. e RocA significantly decreased the metastasis level of AsPC-1 cells in vivo whereas Mycro3 and the combination treatment did not. f RocA significantly suppressed subcutaneous tumor xenograft growth. $\mathbf{g}$ Western blot results showed that RocA notably decreased the expression of elF4A1, c-MYC, and snail, but increased the expression of E-cadherin in subcutaneous tumor grafts. ${ }^{*} P<0.05,{ }^{* * *} P<0.01,{ }^{* * *} P<0.001$, NS: no statistical significance 
miR-9 axis. Furthermore, depletion of either eIF4A1 or c-MYC significantly decreased the EMT level and metastasis in vitro and in vivo, and vice versa. However, regulating translation is extremely complicated. c-MYC is likely not the only target for eIF4A1 to promote EMT and metastasis and it was reported that c-MYC overexpression could further upregulate eIF4A1 [31, 38]. In this study, we found that eIF4A1 overexpression rescued the diminished EMT and metastasis capabilities of c-MYC knockdown pancreatic cancer cells in vitro and in vivo. Nevertheless, the compensation for c-MYC depletion was incomplete, as the metastatic capabilities of e-U-M$D$ cells were significantly weaker than those of e-U cells whereas stronger than those of M-D cells. This result indicated that even if there are other targets of eIF4A1, c-MYC still plays a vital role in eIF4A-mediated EMT and metastasis.

Similar to KRAS, c-MYC has traditionally been deemed an "undruggable" target. However, Mycro3 is a novel anti-MYC compound inhibits c-MYC activity through MYC dimerization [23, 39]. As previously mentioned, the relationship between eIF4A and c-MYC was not simply unidirectional; thus, simultaneously targeting eIF4A and c-MYC was employed, and the efficacy and safety of this regimen were evaluated. Our work demonstrated that RocA or Mycro3 either alone or in combination notably repressed the EMT level in vitro. However, the combination treatment did not show any superiority to the monotherapies. Similar to the in vitro results, RocA was the only reagent that exerted a significant antimetastatic effect in vivo among the two monotherapy and combination treatment. The reason behind this result is still unknown, but we can speculate from preparatory experiments that combining RocA and Mycro3 increased the risk of death, as the mice were not tolerant of the original dose. The dose of RocA in previous studies ranged from $1.4 \mathrm{mg} / \mathrm{kg}$ once on an alternate day to $5 \mathrm{mg} /$ $\mathrm{kg}$ daily for cancer treatment [26, 35, 40-45], which was quite extensive. Further toxicity analysis is required to elucidate the most accurate treatment dose selection. All previous studies using RocA for pancreatic cancer treatment was administered $5 \mathrm{mg} / \mathrm{kg} / \mathrm{d}(26,41)$. However, our study showed that mid-dose $2.5 \mathrm{mg} / \mathrm{kg}$ every other day RocA monotherapy also dramatically suppressed eIF4Amediated pancreatic cancer cell metastasis.

\section{Conclusions}

Collectively, we demonstrated that eIF4A1 overexpression downregulated E-cadherin expression through the c-MYC/miR-9 axis (Fig. 6), which promoted EMT and the metastasis of pancreatic cancer cells in vitro and in vivo. In addition, ectopic expression of eIF4A1 partially rescued the inhibition of EMT and metastasis mediated by c-MYC-depletion. Moreover, RocA monotherapy

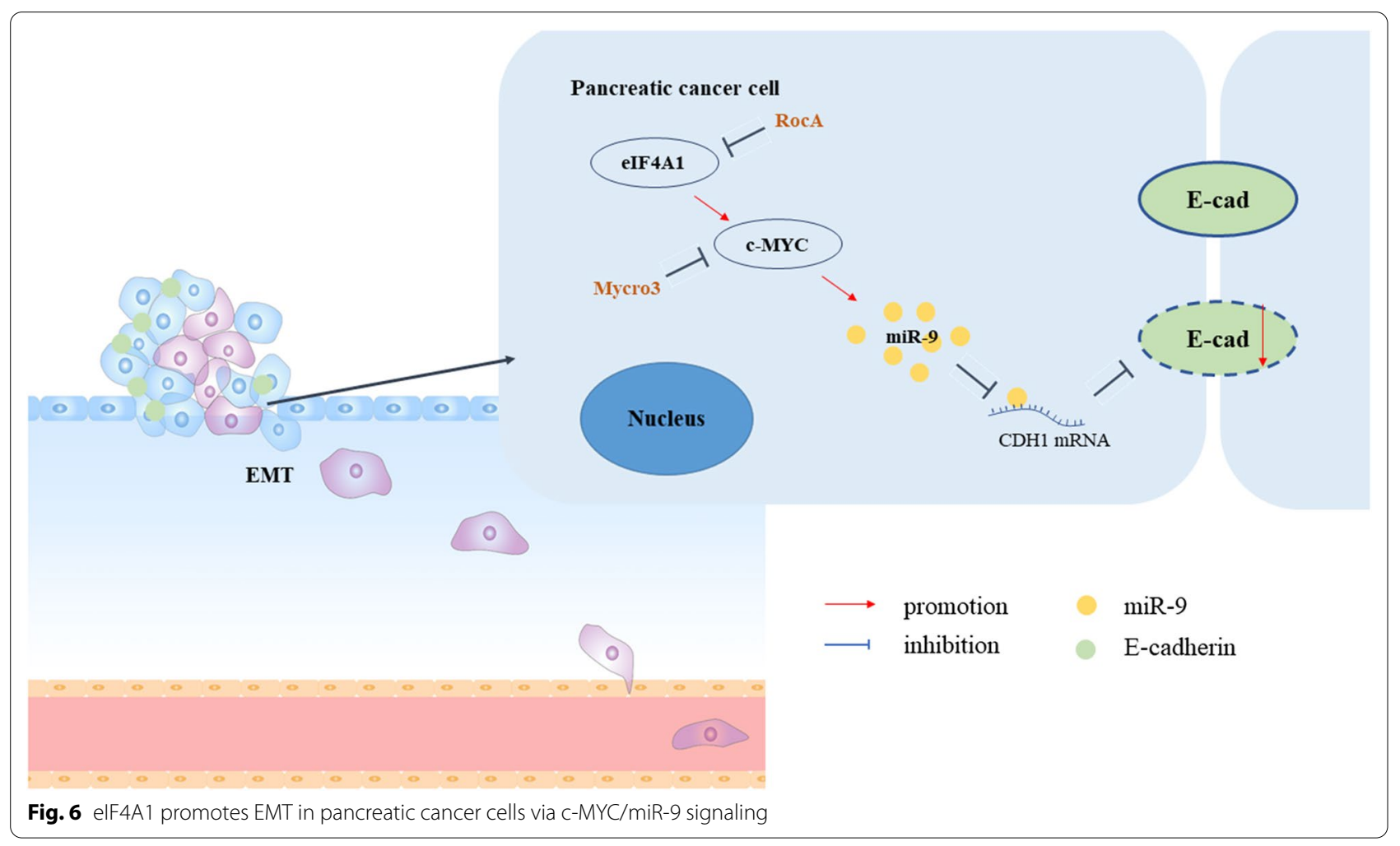


was superior to the combination treatment at the current dose, possibly due to intolerance. Our data indicated that eIF4A1 is a satisfactory biomarker for PDAC prognosis, and targeting eIF4A1 provides a promising therapeutic strategy for overcoming PDAC metastasis.

\section{Abbreviations}

PDAC: Pancreatic ductal adenocarcinoma; elF: Eukaryotic translation initiation factor; EMT: Epithelial mesenchymal-transition; RocA: Rocaglamide; TCGA: The Cancer Genome Atlas; GTEx: Genome tissue expression; 5'-UTR: 5'-Untranslated region; FC: Fold change; FDR: False discovery rate; DEP: Differential expressed protein.

\section{Supplementary Information}

The online version contains supplementary material available at https://doi. org/10.1186/s12935-021-02390-0.

Additional file 1: Fig. S1. SDS-PAGE of elF4A1-knockdown AsPC-1 cells. The protein abundance at $49 \mathrm{kDa}$ (the molecular weight of c-MYC) remarkably decreased after the knockdown of elF4A1.

Additional file 2: Fig. S2. Analysis of the correlation of elF4A1 and C-MYC using data from TCGA and GTEx databases. (a). The expression of elF4A1 and C-MYC in tumor tissues and normal tissues of PDAC patients were analyzed. c-MYC is positively correlated with elF4A1 $(n=350, r=0.475$, $P=2.26 \mathrm{e}-16$, Spearman correlation). (b). c-MYC and elF4A1 are positively correlated in most cancer types including PDAC.

Additional file 3: Fig. S3. Fluorescence in situ hybridization (FISH) assay showed that treatment with $100 \mathrm{nM}$ RocA for $12 \mathrm{~h}$ significantly decreased the miR-9 expression in AsPC-1 cells.

\section{Acknowledgements}

We sincerely thank all staff from the Tongji Hospital, Tongji Medical College, HUST for their effort in project execution. We also thank the statistical staffs (Ping Yin, Chang Shu) at the Department of Epidemiology and Biostatistics, School of Public Health, Tongji Medical College, HUST and Hepatic Surgery Centre, Tongji Hospital, Tongji Medical College, HUST and support from Shoujiang Tang, University of Mississippi Medical Center. And we deeply thank the supportive data uploaded by Karina Chan et al. (https://doi.org/10.1038/ s41467-019-13086-5, GSE120159) from Columbia University Medical Center.

\section{Authors' contributions}

B.C. and L.Z. designed the study and performed data analysis. Y.Z. and Y.W. performed acquisition of data. Y.Z. drafted the manuscript. W.Y. provided critical revision of the manuscript for important intellectual content. W.C., S.B., W.P., M.Z. and Y.L. performed technical support. Y. D. provided pathological verification. B.C. and L.Z. performed study supervision. All authors have read and approved the manuscript.

\section{Funding}

This work is supported by the National Natural Science Foundation of China, granted number: No. 81802427), and the Wuhan Science and Technology Bureau granted number: No. 20190207010114310.

\section{Availability of data and materials}

The datasets used and/or analyzed during the current study available from the corresponding author on reasonable request.

\section{Declarations}

\section{Ethics approval and consent to participate}

The study concerning the clients' right to privacy. The study was approved by the Ethical Committee of Tongji Hospital, Tongji Medical College, Huazhong University of Science and Technology and was conducted according to the principles of the Declaration of Helsinki. Written informed consent was obtained from the subject, and his study considered declaration of Helsinki as a statement of ethical principles. Informed consent was obtained from all patients.

\section{Consent for publication}

Not applicable.

\section{Competing interests}

Drs. Yuchong Zhao, Yun Wang, Wei Chen, Shuya Bai, Wang Peng, Mengli Zheng, Yilei Yang, Bin Cheng, and Zhou Luan have no conflicts of interest or financial ties to disclose.

\section{Author details}

'Department of Gastroenterology and Hepatology, Tongji Hospital, Tongji Medical College, Huazhong University of Science and Technology, Jiefang Avenue No. 1095, Wuhan 430030, China. ${ }^{2}$ Departement of Hepatobiliary and Pancreatic Surgery, The First Affiliated Hospital of Zhengzhou University, Jianshe East Road No. 1, Zhengzhou, China.

Received: 14 September 2021 Accepted: 3 December 2021

Published online: 14 December 2021

\section{References}

1. Sung H, Ferlay J, Siegel RL, Laversanne M, Soerjomataram I, Jemal A, et al. Global cancer statistics 2020: GLOBOCAN estimates of incidence and mortality worldwide for 36 cancers in 185 countries. CA Cancer J Clin 2021;70(4):313.

2. Siegel RL, Miller KD, Fuchs HE, Jemal A. Cancer Statistics, 2021. CA Cancer J Clin. 2021;71(1):7-33.

3. Pereira SP, Oldfield L, Ney A, Hart PA, Keane MG, Pandol SJ, et al. Early detection of pancreatic cancer. Lancet Gastroenterol Hepatol. 2020. https://doi.org/10.1016/S2468-1253(19)30416-9.

4. Rhim AD, Mirek ET, Aiello NM, Maitra A, Bailey JM, McAllister F, et al. EMT and dissemination precede pancreatic tumor formation. Cell. 2012;148(1-2):349-61.

5. Magliano MPD, Logsdon CD. Roles for KRAS in pancreatic tumor development and progression. Gastroenterology. 2013;144(6):1220-9.

6. Hendifar AE, Blais EM, Ng C, Thach D, Gong J, Sohal D, et al. Comprehensive analysis of KRAS variants in patients (pts) with pancreatic cancer (PDAC): clinical/molecular correlations and real-world outcomes across standard therapies. J Clin Oncol. 2020;38(15_suppl):4641.

7. Varga A, Soria JC, Hollebecque A, LoRusso P, Bendell J, Huang SMA, et al. A first-in-human phase I study to evaluate the ERK1/2 inhibitor GDC-0994 in patients with advanced solid tumors. Clin Cancer Res. 2020;26(6):1229-36.

8. Van Cutsem E, Hidalgo M, Canon JL, Macarulla T, Bazin I, Poddubskaya $\mathrm{E}$, et al. Phase I/II trial of pimasertib plus gemcitabine in patients with metastatic pancreatic cancer. Int J Cancer. 2018;143(8):2053-64.

9. Bedard PL, Tabernero J, Janku F, Wainberg ZA, Paz-Ares L, Vansteenkiste $J$, et al. A phase lb dose-escalation study of the oral pan-PI3K inhibitor Buparlisib (BKM120) in combination with the oral MEK1/2 inhibitor trametinib (GSK1120212) in patients with selected advanced solid tumors. Clin Cancer Res. 2015;21(4):730-8.

10. Silvera D, Formenti SC, Schneider RJ. Translational control in cancer. Nat Rev Cancer. 2010;10(4):254-66.

11. Clemens MJ. Targets and mechanisms for the regulation of translation in malignant transformation. Oncogene. 2004;23(18):3180-8.

12. Raza F, Waldron JA, Le Quesne J. Translational dysregulation in cancer: elF4A isoforms and sequence determinants of elF4A dependence. Biochem Soc Trans. 2015;43:1227-33.

13. Boussemart L, Malka-Mahieu H, Girault I, Allard D, Hemmingsson O, Tomasic $\mathrm{G}$, et al. elF4F is a nexus of resistance to anti-BRAF and anti-MEK cancer therapies. Nature. 2014;513(7516):105-9.

14. Gingras AC, Raught B, Sonenberg N. elF4 initiation factors: effectors of mRNA recruitment to ribosomes and regulators of translation. Ann Rev Biochem. 1999;68:913-63.

15. Wiegering $A$, Uthe FW, Jamieson T, Ruoss $Y$, Huettenrauch $M$, Kuespert $M$, et al. Targeting translation initiation bypasses signaling crosstalk 
mechanisms that maintain high MYC levels in colorectal cancer. Cancer Discov. 2015;5(7):768-81.

16. Spriggs KA, Cobbold LC, Jopling CL, Cooper RE, Wilson LA, Stoneley M, et al. Canonical initiation factor requirements of the Myc family of internal ribosome entry segments. Mol Cell Biol. 2009;29(6):1565-74.

17. Yourik P, Aitken CE, Zhou F, Gupta N, Hinnebusch AG, Lorsch JR. Yeast elF4A enhances recruitment of mRNAs regardless of their structural complexity. Elife. 2017;6: e31476.

18. Sodir NM, Swigart LB, Karnezis AN, Hanahan D, Evan Gl, Soucek L. Endogenous Myc maintains the tumor microenvironment. Genes Dev. 2011;25(9):907-16.

19. Ischenko I, Zhi J, Moll UM, Nemajerova A, Petrenko O. Direct reprogramming by oncogenic Ras and Myc. Proc Natl Acad Sci U S A. 2013;1 10(10):3937-42.

20. Ma L, Young J, Prabhala H, Pan E, Mestdagh P, Muth D, et al. miR-9, a MYC/ MYCN-activated microRNA, regulates E-cadherin and cancer metastasis. Nat Cell Biol. 2010;12(3):247-56.

21. Khew-Goodall Y, Goodall GJ. Myc-modulated miR-9 makes more metastases. Nat Cell Biol. 2010;12(3):209-11.

22. Duffy MJ, O'Grady S, Tang M, Crown J. MYC as a target for cancer treatment. Cancer Treat Rev. 2021;94: 102154.

23. Duffy MJ, Crown J. Drugging, "undruggable" genes for cancer treatment: are we making progress? Int J Cancer. 2021;148(1):8-17.

24. Iwasaki S, Floor SN, Ingolia NT. Rocaglates convert DEAD-box protein elF4A into a sequence-selective translational repressor. Nature. 2016;534(7608):558-61.

25. Wu Y, Giaisi M, Kohler R, Chen WM, Krammer PH, Li-Weber M. Rocaglamide breaks TRAIL-resistance in human multiple myeloma and acute T-cell leukemia in vivo in a mouse xenogtraft model. Cancer Lett. 2017;389:70-7.

26. Luan Z, He Y, Alattar M, Chen ZS, He F. Targeting the prohibition scaffoldCRAF kinase interaction in RAS-ERK-driven pancreatic ductal adenocarcinoma. Mol Cancer. 2014;13:11.

27. Sakellariou D, Frankel LB. EIF4A3: a gatekeeper of autophagy. Autophagy. 2021. https://doi.org/10.1080/15548627.2021.1985881.

28. Wang X, Wang R, Bai S, Xiong S, Li Y, Liu M, et al. Musashi2 contributes to the maintenance of $C D 44 v 6+$ liver cancer stem cells via notch1 signaling pathway. J Exp Clin Cancer Res. 2019;38(1):505.

29. Stellas D, Szabolcs M, Koul S, Li Z, Polyzos A, Anagnostopoulos C, et al. Therapeutic effects of an anti-Myc drug on mouse pancreatic cancer. J Natl Cancer Inst. 2014;106(12): dju320.

30. Jackstadt R, Hermeking H. MicroRNAs as regulators and mediators of c-MYC function. Biochim Biophys Acta. 2015;1849(5):544-53.

31. Lin CJ, Cencic R, Mills JR, Robert F, Pelletier J. c-Myc and elF4F are components of a feedforward loop that links transcription and translation. Cancer Res. 2008;68(13):5326-34.

32. Dang CV, Reddy EP, Shokat KM, Soucek L. Drugging the "undruggable" cancer targets. Nat Rev Cancer. 2017;17(8):502-8.
33. Boj SF, Hwang Cl, Baker LA, Chio IIC, Engle DD, Corbo V, et al. Organoid models of human and mouse ductal pancreatic cancer. Cell. 2015;160(1-2):324-38.

34. Pelletier J, Graff J, Ruggero D, Sonenberg N. Targeting the elF4F translation initiation complex: a critical nexus for cancer development. Can Res. 2015;75(2):250-63.

35. Yao C, Ni Z, Gong C, Zhu X, Wang L, Xu Z, et al. Rocaglamide enhances NK cell-mediated killing of non-small cell lung cancer cells by inhibiting autophagy. Autophagy. 2018;14(10):1831-44.

36. Müller D, Shin S, Goullet de Rugy T, Samain R, Baer R, Strehaiano M, et al. elF4A inhibition circumvents uncontrolled DNA replication mediated by 4E-BP1 loss in pancreatic cancer. JCl Insight. 2019. https://doi.org/10 1172/jci.insight.121951.

37. Chan K, Robert F, Oertlin C, Kapeller-Libermann D, Avizonis D, Gutierrez J, et al. elF4A supports an oncogenic translation program in pancreatic ductal adenocarcinoma. Nat Commun. 2019;10:16.

38. Castell A, Larsson L-G. Targeting MYC translation in colorectal cancer. Cancer Discov. 2015;5(7):701-3.

39. Madden SK, de Araujo AD, Gerhardt M, Fairlie DP, Mason JM. Taking the Myc out of cancer: toward therapeutic strategies to directly inhibit c-Myc. Mol Cancer. 2021;20(1):3.

40. Luan Z, He Y, He F, Chen Z. Rocaglamide overcomes tumor necrosis factor-related apoptosis-inducing ligand resistance in hepatocellular carcinoma cells by attenuating the inhibition of caspase-8 through cellular FLICE-like-inhibitory protein downregulation. Mol Med Rep. 2015;11(1):203-11.

41. Wang B, Li Y, Tan F, Xiao Z. Chinese herb derived-Rocaglamide A is a potent inhibitor of pancreatic cancer cells. Am J Transl Res. 2016;8(2):1047-54.

42. Doudican NA, Orlow SJ. Inhibition of the CRAF/prohibitin interaction reverses CRAF-dependent resistance to vemurafenib. Oncogene. 2017;36(3):423-8

43. Wu Y, Giaisi M, Köhler R, Chen WM, Krammer PH, Li-Weber M. Rocaglamide breaks TRAIL-resistance in human multiple myeloma and acute T-cell leukemia in vivo in a mouse xenogtraft model. Cancer Lett. 2017:389:70-7.

44. Yurugi $\mathrm{H}$, Marini F, Weber $\mathrm{C}$, David K, Zhao Q, Binder $\mathrm{H}$, et al. Targeting prohibitins with chemical ligands inhibits KRAS-mediated lung tumours. Oncogene. 2017;36(33):4778-89.

45. Chang LS, Oblinger JL, Burns SS, Huang J, Anderson LW, Hollingshead $M G$, et al. Targeting protein translation by Rocaglamide and Didesmethylrocaglamide to treat MPNST and other sarcomas. Mol Cancer Ther. 2020;19(3):731-41.

\section{Publisher's Note}

Springer Nature remains neutral with regard to jurisdictional claims in published maps and institutional affiliations.
Ready to submit your research? Choose BMC and benefit from:

- fast, convenient online submission

- thorough peer review by experienced researchers in your field

- rapid publication on acceptance

- support for research data, including large and complex data types

- gold Open Access which fosters wider collaboration and increased citations

- maximum visibility for your research: over $100 \mathrm{M}$ website views per year

At BMC, research is always in progress.

Learn more biomedcentral.com/submissions 